\title{
Abusive Supervision Scale Development in Indonesia
}

\author{
Fenika Wulani, ${ }^{*}$ B M Purwanto, and Hani Handoko \\ ${ }^{a}$ Faculty of Business, Widya Mandala Catholic University, Surabaya, Indonesia

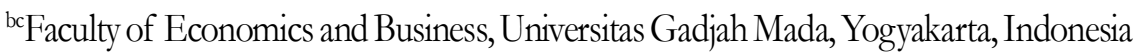

\begin{abstract}
The purpose of this study was to develop a scale of abusive supervision in Indonesia. The study was conducted with a different context and scale development method from Tepper's (2000) abusive supervision scale. The abusive supervision scale from Tepper (2000) was developed in the U.S., which has a cultural orientation of low power distance. The current study was conducted in Indonesia, which has a high power distance. This study used interview procedures to obtain information about supervisor's abusive behavior, and it was also assessed by experts. The results of this study indicated that abusive supervision was a 3 -dimensional construct. There were anger-active abuse ( 6 items), humiliationactive abuse (4 items), and passive abuse (15 items). These scales have internal reliabilities of $0.947,0.922$, and 0.845 , in sequence.
\end{abstract}

\begin{abstract}
Abstrak: Studi ini bertujuan untuk mengembangkan skala abusive supervision di Indonesia. Studi ini dilakukan pada konteks dan metode pengembangan skala yang berbeda dari skala abusive supervision milik Tepper (2000). Tepper (2000) mengembangkan skalanya di US., yang masyarakatnya secara umum memiliki budaya jarak kekuasaan rendah. Studi ini dilakukan di Indonesia yang memiliki budaya jarak kekuasaan tinggi. Studi ini menggunakan wawancara untuk menghasilkan informasi mengenai perilaku atasan yang abusif. Selanjutnya daftar perilaku tersebut dinilai oleh para pakar. Hasil studi ini mengindikasikan bahwa abusive supervision merupakan konstruk tiga dimensi. Ketiga dimensi tersebut adalah abusif aktif-kemarahan (6 indikator), abusif aktif-penghinaan ( 4 indikator), dan abusif pasif ( 15 indikator). Skala ini, masing-masing ketiga dimensinya memiliki reliabilitas 0,$947 ; 0,922$; and 0,845 ; secara berurutan.
\end{abstract}

Keywords: abusive supervision; dimensionality; Indonesia; scale development 


\section{Introduction}

In a working relationship between a supervisor and his or her subordinate, the destructive behavior of a supervisor toward subordinates cannot be avoided. One of the constructs used to investigate the improper behavior of superiors to their subordinates is abusive supervision. Since the early 2000s, this construct has been widely studied - all studies showed that abusive supervision had a negative impact on its victims, who were subordinates (e.g. Tepper et al. 2000, 2007, 2008, 2009; Mitchell and Ambrose 2007; Thau et al. 2009; Lian et al. 2012).

Abusive supervision is a construct of negative behavior in an organization with the focus being on the treatment by leaders to their subordinates. In the various studies, most of the abusive supervision construct was measured using a scale by Tepper (2000). A scale was developed for abusive supervision, and mostly used in studies conducted in the U.S. However, referring to divergence perspective, culture has a primary effect on the value of work and personal values (Rotundo and Xie 2008). Tepper (2000) argued that in countries with different cultures, different notions may come up of what constitutes abusive behavior. This is consistent with Aquino et al. (2004) who stated that individual perceptions are often biased by their cultural orientation. Furthermore, according to Kirkman, Chen, Farh, Zhen, and Lowe (2009), cultural values which are held by an individual determine the individual's reaction to aspects of his work. One of the dimensions of culture that is very relevant to leadership studies is power distance. This is because it can explain how subordinates perceive their leader (Lian et al. 2000).

Kirkman et al. (2009) argued that compared with other cultural dimensions offered by Hofstede's study (e.g. individualism-collectivism, uncertainty-avoidance, and masculinity-femininity), power distance has a more direct relationship to leadership. In addition, power distance as a cultural value also plays an important role in explaining the behavior of bullying and harassment in the organization (Hofstede 1994, in Galpertin 2002). Samnani (2013) explained that, with regard to Hofstede's dimensions, only the dimension of individualism-collectivism and power distance have a relational nature, because they describe how individuals relate to one another. But the individualism-collectivism dimension reflects more on the relationship between individuals in the same level of hierarchy. While the dimension of power distance describes the relationship between people at different levels of hierarchy (Samnani 2013). This is consistent with the concept of power distance which is the individual's beliefs about the status, authority, and power in organizations (Kirkman et al. 2009).

Employers in the countries with a high power distance have unlimited power and control over their subordinates (Khatri 2009). Therefore, it is possible that abusive supervision is more common in countries with that high power distance culture (Tepper 2007; Lian et al. 2000). However, most of the research into abusive supervision and its scale development has been conducted in the U.S. where there is a low power distance (Ralston et al. 2005). There has been limited research on abusive supervision conducted in a country with a high power distance culture, especially in understanding the supervisor's behavior that is regarded as abusive treatment. One of the countries that has a high power distance cultural value is Indonesia (Hofstede 2007). Empirically, the studies by Wolf (1999 in Nourse 2002) and Hancock (2000) found that women workers in Indonesia experience 
abusive behavior from their manager. However, there has been a lack of studies of abusive supervision conducted in Indonesia.

In addition, although the abusive supervision scale from Tepper (2000) has been widely used in various studies, it has never been tested psychometrically (Tepper 2007). Furthermore, there was a contradiction about the dimensionality of the abusive supervision scale. The initial scale that was developed by Tepper (2000) showed an unidimensional result. Whereas, Mitchell and Ambrose (2007) found that this construct has two dimensions of abusive behaviors, namely active and passive abuse.

Given the importance of studies to investigate this construct -because of its negative impact for employees and their organization as a whole, as well as a need to find a measure for abusive supervision which is appropriate for using in studies in different contexts (in their cultural value orientations), then this current research explores the items of abusive supervision within an Indonesian sample. This study identified the indicators of abusive supervision using a sample of Indonesian workers, to try to know whether abusive supervision reflects a different meaning in the Indonesian culture. Results of this study provide an initial validation of the abusive supervision scale, especially to address the issue of whether the abusive behavior by supervisors is interpreted in the same way by the participants in different countries, which have different cultural values to those of the U.S., and whether the scale is a unidimensional or multidimensional.

\section{Theoretical Background}

\section{Abusive Supervision and Indonesian Culture}

Tepper (2000: 178) defined abusive supervision as "subordinates' perceptions of the extent to which supervisors engage in the sustained display of hostile verbal and nonverbal behaviors, excluding physical contact." The behavior of supervisors, as shown in the construct indicators, such as ridiculing the subordinate, telling the subordinate his/ her thoughts or feelings are stupid, giving the subordinate the silent treatment, putting the subordinate down in front of others, invading the subordinate's privacy, constant reminders of the subordinate's past mistakes and failures, doesn't give the subordinate credit for jobs requiring a lot of effort, placing blame on the subordinate to save himself/herself embarrassment, breaking promises he/she makes, expressing anger at the subordinate when he/she is mad for another reason, making negative comments about the subordinate to others,_being rude to the subordinate, does not allow the subordinate to interact with his/her co-workers, telling the subordinate he/she is incompetent, and lying to the subordinate (Tepper 2000).

Abusive supervision is also said as a psychologically abusive behavior that continues to exist and be directed at subordinates (Tepper 1998, in Nelson 1998). Various empirical studies have found other forms of psychological abuse. For example, referring to Shepard and Campbell (1992, in Nelson 
1998), psychologically abusive behavior in intimate relationships (male and female) includes six sub-categories, that is passive abuse (humiliating and degrading treatment), insulation (to limit social contact), intimidation (actions or gestures to frighten), threat (harm, hazard), using male privilege (demanding obedience based on faith in the rights of man), and economic abuse (restrictions on financial resources). While Neuman and Baron (1997, in Nelson 1998) defined abusive supervisor behavior as including the use of obscenities, unfair performance evaluations, spreading rumors, and providing adverse information.

Tepper (2007) suggested that abusive behavior by superiors to subordinates potentially more often occurs in countries with a high culture of power distance. A society with a high power distance, particularly in the superior-subordinate relationship, has subordinates who would expect their superior to be a benevolent and autocratic leader, as well as one who provides them with some direction (Hostede 1998), they fear a negative evaluation from their superiors (Liew et al. 2011), they are more accepting of differences in their status and treatment (Mamman et al. 1996; at Paine and Organ 2000), they accept being controlled by tight rules and procedures, as well as they do not want to oppose their superiors (Khatri 2009), and they are more tolerant to a tyrannical and autocratic leader (Padilla et al. 2007). Therefore, in the high power distance, superiors have almost unlimited control and power over their subordinates (Katri 2009). According to Hofstede (2007), Asian countries, including Indonesia, have this high power distance.

In Indonesia, the culture of high power distance is reflected by Javanese culture. The Javanese are the largest ethnic group in Indonesia (Wright and Tellei, 1993). The Javanese leader is expected to play the role of a father who has authority and correct moral values, as well as showing benevolent behavior (Irawanto and Ramsey 2011). In Javanese culture, subordinates will respect positively to their leader who is not cruel and abrasive, and who acts fairly (Irawanto and Ramsey 2011). Based on those cultural values, it can be argued that even though the leaders have unlimited power, they should have positive morals and behavior. Consequently, if the leaders do not have those values, subordinates will perceive them negatively.

\section{Abusive Supervision Scale}

The abusive supervision scale that was developed by Tepper (2000) using a set of non-physical abusive behaviors derived from the kinds of interpersonal relationships outside the relationships between supervisors and subordinates. This scale also was built from literatures which describes the actions suited to abusive supervision, and of the physical behavior which occurred in personal relationships (male and female). Furthermore, this set of behaviors was given to $68 \mathrm{MBA}$ students to classify them in the category of nonphysical abuse, physical abuse, and non abusive behaviors.

Tepper's scale was a unidimensional measure, with 15 indicators (Table 1.). Some researchers combined this scale with measures of social undermining (Zellars et al. 2002) and verbal aggression (Thau et al. 2009). Several other researchers (Zellars et al. 2002; Duffy and Farrier 2003; Aryee et al. 2007; Detert et al. 2007; Harris et al. 2007; Mitchell and Ambrose 2007; Burris et al. 2008; Thau et al. 2009) used the short version of Tepper's scale (2000). But the study of Mitchell and Ambrose (2007), which tested the construct validity of the 15 items of Tepper's abusive supervision scale (2000), 
introduced an abusive supervision scale as multidimensional. This multidimensional scale included active abusive behavior (lead- ing to verbal abuse) and passive abusive behavior (leading to nonverbal abuse).

\section{Table 1. Tepper (2000) Scale Items}

\begin{tabular}{|c|c|}
\hline No. & Items \\
\hline 1. & Ridicules me \\
\hline 2. & Tells me my thoughts or feelings are stupid \\
\hline 3. & Gives me the silent treatment \\
\hline 4. & Puts me down in front of others \\
\hline 5. & Invades my privacy \\
\hline 6. & Reminds me of my past mistakes and failures \\
\hline 7. & Doesn't give me credit for jobs requiring a lot of effort \\
\hline 8. & Blames me to save himself/herself embarrassment \\
\hline 9. & Breaks promises he/she makes \\
\hline 10. & Expresses anger at me when he/she is mad for anotherReason \\
\hline 11. & Makes negative comments about me to others \\
\hline 12. & Is rude to me \\
\hline 13. & Does not allow me to interact with my coworkers \\
\hline 14. & Tells me I'm incompetent \\
\hline 15. & Lies to me \\
\hline
\end{tabular}

Note: The items were prefaced with the statement, "My boss . .." Respondents used a five-point response scale where 1 was "I cannot remember him/her ever using this behavior with me," 2 was "He/ she very seldom uses this behavior with me," 3 was "He/she occasionally uses this behavior with me," 4 was " $\mathrm{He}$ /she uses this behavior moderately often with me," and 5 was " $\mathrm{He} / \mathrm{she}$ uses this behavior very often with me."

Source: Tepper (2000). 


\section{Methods and Results}

\section{Study 1 - Instrument Development}

\section{Stage 1: Item generation}

Exploration of the abusive supervision items was done through interviews with 23 participants. These participants were employees that work as marketing staff (in various industries), administrative staff (in various industries), customer service officers (CSO) and banking tellers (the banking industry). Referring to tenure, 13 participants have worked for_between 1-3 years, 5 participants had worked for 5 years and over, 3 of the participants have worked for between 3-5 years, and 2 participants have worked for less than 1 year.

The interviews were conducted privately. The researcher met personally with each participant. At the beginning of the interview, the interviewees were given the definition of abusive supervision from Tepper (2000). Further, semi-structured interviews were conducted with the participants. They were asked to recall if in the last 6 months they had experienced and/or seen painful treatment by their immediate supervisor according to the definition given. Finally, participants were asked to explain in detail what kind of treatment they had experienced. The entire interviews process was recorded.

These interviews resulted in 163 items of supervisor abusive behaviors. Because some respondents mentioned the same abusive behavior, we narrowed down the amount of those behaviors. A total of 99 behaviors were then submitted to panelists/experts who would conduct face validity for these behaviors.

\section{Stage 2: Item review}

At this stage we conducted an analysis of abusive supervision measurement instruments by adopting The Lawshe procedure (1975). This procedure involves an evaluation process of the instrument by individuals who have knowledge of the concepts being measured. The list of the 99 behaviors of abusive supervision, resulting from study 1, was submitted to 6 expert panelists. The six experts included two subordinates - who worked respectively as a secretary of a manufacturing company, and an administrative staff from a distributor company; two supervisors - who worked as the head of a branch of a financial services firm, and a supervisor in a manufacturing firm, and two consultants who have backgrounds in psychology education.

The expert panelists conducted a face validity analysis referring to the definition of abusive supervision or improper behaviors by superiors to subordinates. There are three important things in this definition: first, the behavior of the unpleasant/rude/adverse (hostile) kind; second, behavior of a nonphysical nature, and the third, behavior being repeated. The result of the analysis was quantified by calculating the Content Validity Ratio (CVR). The panelists were given a copy of the interview results and asked to respond to the_abusive supervision relevance of each behavior on a 3-point scale; $1=$ not relevant, $2=$ important (but not essential), $3=$ essential. The responses of the six experts were calculated based on the formula CVR $[\mathrm{CVR}=(\mathrm{n} / 2) /(\mathrm{N} / 2)] .{ }^{1}$

\footnotetext{
${ }^{1} \mathrm{n}$ is an frequency count of the number of panelists rating them as either $3=$ essential or $2=$ important. $\mathrm{N}$ is the total number of panelist (Templeton et al. 2002)
} 
CVR will be statistically significant if more than 50 percent of the panelists assess certain items as 'essential' (Templeton et al. 2002). While referring to the Lawshe table (1975), for assessment by the six panelists, the minimum CVR value considered to be significant (at the 0.05 level) is 0.99 . However, Lawshe (1975) stated that although using a CVR to drop an item, researchers may also consider traditional item analysis procedures. The use of the Lawshe table is not rigid, as stated by Shultz and Whitney (2005), if the CVR value is positive, although less than the requirements of Lawshe's table, it can still be used if the amount of panelist was relatively small. In this study, items with a value of CVR 0.67 was retained by consideration of the fact that five of the six panelists rate the item as being important and essential, and these items would still be tested again on a larger sample. Based on these considerations, there were 57 abusive behaviors by supervisor that can be maintained. Based on further analysis, there were several items considered that had the same meaning. Some other items showed non-specific objects (not specifically against individual employees). Based on this analysis, there were 16 items which were dropped. Thus, for subsequent analysis we used the remaining 41 items.

\section{Study 2: Instrument refinement}

In the second study, according to the Ideal Survey Attributes (ISA) of Maholtra and Grover (1998; in Templeton et al. 2002), we tested the psychometric properties of the abusive supervision instruments (indicators) that have been revised. Testing of the abusive supervision scale was done by using a questionnaire survey. A total of 103 questionnaires were distributed to respondents from various fields of employment, and types of organizations in Surabaya (the second larg- est city in Indonesia). Respondents were asked to respond to abusive supervision on a 41 point Likert 5 -point scale $(1=\mathrm{TDM}=$ cannot remember the abusive behavior of my supervisor, up to, $5=\mathrm{SS}=$ my supervisor very often do abusive behavior on $\mathrm{me}$ ). There were 101 questionnaires completed and returned.

Most respondents were female (64.4\%), aged between 25 to less than 35 years old $(58.4 \%)$, who had been working for 1 to less than 5 years $(52.5 \%)$. They worked in various fields of employment and industries. Most respondents worked in the field of administration $(37.6 \%)$, accounting $(12.9 \%)$, marketing $(7.9 \%)$, and customer service $(6.9 \%)$. The others worked as programmers, secretaries, reporters, supervisors, analysts, quality controllers, managers, tellers, HRD staff, foremen, designers (pharmaceutical companies), teachers and lecturers, estimators, and auditors. There were four respondents who did not fill in their occupation. Most respondents worked in the trade business types (such as distributors) which is about 31.7 percent, financial services (16.8\%), manufacturing $(11.9 \%)$, tourism services $(5 \%)$, health services $(3 \%)$, retail $(2 \%)$, and the other 28.7 percent worked in various types of organizations such as the media, IT, education, and ship repair services. There was one respondent who did not fill in the kind of organization where he works.

The 41 indicators were examined by exploratory factor analysis (EFA) to identify the relationship between the abusive supervision items and to determine the dimensionality of this construct. We tested this EFA by using principal component analysis with varimax rotation. EFA Test results showed that the three factors model was the most likely model for further analysis. In order to retain items for our scale construction, we 
used a factor loading at least 0.4. Model with 3 factors dropped 13 items and maintained 28 items. These three factors formed explained 66.015 percent of the total variance. The first factor was composed of 13 indicators, second factor was composed of 10 indicators, and third factor was composed of 5 indicators. The three factors model was then tested for its reliability by using Cronbach's Alpha reliability. The analysis showed that in the third factor, there was one indicator that had a low reliability value. After this indicator was dropped, the reliability test showed that each factor has a fairly high reliability (a $>0.7)$. These results indicated a high internal consistency, and that there was a high inter-correlation between indicators (Coltman et al. 2008).

\section{Study 3 - Scale validation}

A validation test of the three factors was conducted in the third study. In this study we also tested the convergent of abusive supervision's construct. In testing of this convergent validity, we analyzed the correlation between abusive supervision that was developed in this study and the 15 point scale of abusive supervision of Tepper (2000).

A total of 706 respondents participated in this study. Questionnaires were distributed to respondents who worked as 1) nurses and medical support staff in hospitals, 2) backoffice and front-office staff of various banks, 3) administration staff, sales reps, and technicians in various fields of industry in Surabaya, Sidoarjo and Gresik; the three cit- ies of trade in Indonesia. Most of the respondents were women (55.4\%) and had been working with their current supervisor for 1 to less than 5 years $(45.8 \%)$. Distribution of the questionnaires was carried out by 79 coordinators of distribution. Respondents were asked to respond on a 121 items Likert 5point scale $(1=\mathrm{TDM}=$ cannot remember the abusive behavior of my supervisor, up to, $5=$ $\mathrm{SS}=$ my supervisor very often do abusive behavior on me).

\section{Dimensionality Testing}

We examined the construct validity of the three factors model generated in the second study by using an exploratory factor analysis/EFA and confirmatory factor analysis/ CFA. The EFA testing was done by using a principal component analysis with oblimin rotation, and the minimum cut-off at the loading factor was 0.4. As in the second study, the EFA produced three dimensions of abusive supervision (Table 2.). The dimensions were anger-active abuse, humiliation-active abuse, and passive abuse. The analysis showed that to obtain a measure of convergence, there are several indicators that should be dropped (i.e.: passive abuse1/ap1 and passive abuse2/ap2).

Furthermore, in order to cross-validate the three-factor solution obtained by the EFA, we performed a CFA. The model provided an acceptable fit to the data, $\chi^{2}(\mathrm{df}=$ $272, \alpha=0.05)=1578.501, \mathrm{CMIN} / \mathrm{df}=5.803$, RMSEA $=0.083$, GFI $=0.833$, AGFI $=0.8$, and $\mathrm{TLI}=0.887$ 
Table 2. The Result of Factor Analysis

Indicator
Factor Loadings

\begin{tabular}{lll}
1 & 2 & 3 \\
\hline
\end{tabular}

aa1. My supervisor says something rude to me 0.817

aa2. My supervisor angry to me out loud

aa3. My supervisor angry to me with a very high level of emotion

aa4. My supervisor angry to me but never explained what I should do

aa5. My supervisor scolds me in front of others

0.756

aa6. My supervisor reprimands me in a high intonation

aa7. My supervisor says I am stupid

aa8 My supervisor ridicules me

aa10. My supervisor hits the table hardly when angry at me

ap2. My supervisor compares me with other subordinates in front of others

ap3. My supervisor gives the impression as if the success of a job is because of his/her effort, not because of mine.

ap4. My supervisor gives me the silent treatment

ap6. My supervisor gives orders without understanding my difficulties

ap7. My supervisor treats me unfairly

ap8. My supervisor does not provide important information about the kinds of the reward will I receive if I can complete the task

ap9. My supervisor does not keep his/her promise to me

ap10. My supervisor does not trust me

ap11. My supervisor does not appreciate my hard work

0.764

ap12. My supervisor does not give important information to me, related to task completion

ap13. My supervisor accuses me of the mistake I did not do 
Table 2. (Continued)

Indicator
Factor Loadings

$\begin{array}{lll}1 & 2 & 3\end{array}$

aa1. My supervisor says something rude to me

0.817

ae1. My supervisor forces me to work up to longer hours of work without giving compensation

ae2. My supervisor forces me to keep working even in the rest hour 0.666

ae3. My supervisor orders me to do a task that does not make sense $\quad 0.688$

ae4. My supervisor asks me to perform duties beyond the job description without giving compensation

Notes: 1. Indicators in Table 1 were results of EFA test on the study of 3.

2. Bold statements/indicators were indicators which were dropped on the study 3 as result of EFA test (the dimensions of the passive abuse).

3. Factor 1 is passive abuse $(a=0.947)$, factor- 2 is anger-active abuse $(a=0.922)$, and factor 3 is humiliation-active abuse $(a=0.845)$. Reliability testing conducted for indicators that are not dropped. These factors explain (in sequence) 51.662 percent, 6.868 percent, and 4.747 percent of the total variance $(n=706)$.

We also compared the three-factor model to a single-factor model that combined all abusive supervision items in a one-factor abusive model, $\chi^{2}(\mathrm{df}=324,5 \%)=3270.275$, $\mathrm{CMIN} / \mathrm{df}=10.093$, RMSEA $=0.114$, GFI $=$ $0.671, \mathrm{AGFI}=0.616$, dan TLI $=0.770$. Our analysis shown that the three-factor model was significantly better than the single-factor model, $\chi^{2}(\mathrm{df}=52, \alpha=0.05)$. The scales showed an acceptable internal consistency, with Cronbach's Alpha reliabilities at 0.92 for anger-active abuse, 0.85 for humiliation-active abuse, and 0.95 for passive abuse. The correlation between anger abuse and humiliation abuse, anger abuse and passive abuse, and humiliation abuse and passive abuse were moderate (sequentially, $\mathrm{r}^{2}=0.71, \mathrm{p}=0.01 ; \mathrm{r}^{2}=$ $0.78, \mathrm{p}=0.01$; and $\left.\mathrm{r}^{2}=0.69, \mathrm{p}=0.01\right)$.
To assess the convergent validity of our abusive supervision scale, we correlated this scale with the 15-item version of Tepper's (2000) abusive supervision scale. The result showed that each dimension of abusive supervision, anger-active abuse, humiliationactive abuse, and passive abuse, significantly correlated with a single dimension of Tepper (in sequence, $\mathrm{r}^{2}=0.759, \mathrm{p}=0.01 ; \mathrm{r}^{2}=0.722$; $\mathrm{p}=0.01 ;$ and $\left.\mathrm{r}^{2}=0.902, \mathrm{p}=0.01\right)$.

\section{Discussion}

This study found that the abusive supervision construct has three dimensions, namely angry-active abuse, humiliation-active abuse, and passive abuse. Angry-active abuse, which consists of 6 indicators, refers to the 
supervisor's verbal behavior with regard to the forms of anger shown, such as scolding the subordinate in front of others, shows anger with no explanation, and anger with a very high level of emotion. Humiliation-active abuse, which consists of 4 indicators, refers to verbal and nonverbal behavior such as taunts and threats from the supervisor, and nonverbal behavior (hitting the table hard) when angry with subordinates. Lastly, passive abuse, which comprised of 15 indicators, refers to the nonverbal behavior of superiors to their subordinates with regard to the completion of their work.

This study found five items that were similar with Tepper's scale(2000), namely the _ supervisor says that his subordinate is stupid, and ridicules them (dimension of humiliation-active abuse), gives the silent treatment, does not keep his promise, and does not appreciate the subordinate's hard work (dimension of passive abuse). Although there are some indicators that are not captured in Tepper's scale (2000), there are several items in this study that have similarities to the findings of abusive behavior from researchers besides Tepper (at the time yet to be named abusive supervision). For example, rude supervisors (Asforth 1997; at Thau et al. 2009; Newman and Baron 1997; in Nelson 1998), supervisors intimidate their subordinates and superiors insulting their subordinates (Keashly et al. 1994: in Nelson 1998), supervisors behave irrationally (Clarke 1995 in Nelson 1998), and supervisors claiming subordinates performance as their performance (Keashly et al. 1994: in Nelson 1998).

The findings from the three dimensions of abusive supervision differs with the abusive supervision's construct that was originally developed by Tepper (2000), which is a unidimensional construct, and also the findings of the 2-dimensional abusive supervi- sion by Mitchell and Ambrose (2007). Among the three dimensions abusive supervision, only the_dimension of humiliation-active abuse has items which show similarity with abusive behavior that are found in the U.S. (i.e. the supervisor ridicules and intimidates the subordinates, and calls them stupid). In regard to the dimension of angry-active abuse, this dimension includes the items which related to angry outbursts. This abusive behavior has been proposed by Keashly et al. (1994). This finding shows that workers in Indonesia, although under a high power distance, they will accept unequal power, but they expect not to_be treated roughly. It is in line with the study by Irawanto and Ramsey (2011) that subordinates, under the Javanese value, show no respect to an autocratic leader that acts cruelly to them. Additionally, intimidation can be considered by subordinates as disrespectful to them (Larson and Kleiner 1992).

Although some items of passive abuse show similarity to abusive items in the U.S., this study found that most of the other items in this dimension have not been uncovered in previous studies of abusive supervision. These items include the provision of information on how to complete the work, and what kind of rewards will be obtained by the subordinates after they complete their task, as well as asking subordinates to completing their tasks beyond their job description and beyond their normal working hours without compensation.

Interestingly, even though Clarke (1995; in Nelson 1998) found that enforcing the rules is an abusive act, in a high power distance, workers expect their leader to give them direction and control them with rules. According to Larson and Kleiner (1992), Asian employees, who tend to have hierarchical relationships, typically will not take the 
initiative because they do not want to take the risk of making any mistakes in their work. It is because, if they make a mistake, they would feel very ashamed in front of their superiors. Consequently, they show respect to the rules and procedures (Larson and Kleiner 1992). Thus, it can be argued that they are expecting their supervisor to provide clear guidelines so that they do not make mistakes on the job. Furthermore, regarding the results of the supervisor not providing possible reward information and asking subordinates to work without compensation, workers in a high power distance have a belief in social investment (Irawanto and Ramsey 2011). It is possible that they expect their leader to give them a reward for their compliance.

In addition to the cultural factor, it is possible that the context of the industry and job function play a role in that difference. In this study, exploratory items of abusive supervision were done by collecting data on participants who worked in the banking industry, marketing and administration positions in various industries. Those types of jobs have complex tasks and the task demand is high, which allows for a wide range of abusive supervision and forms of abuse.

However, the differences in the result in the behavioral indicators of abusive supervision may also be due to the study design in the exploration of abusive supervision items. Tepper (2000) was using a set of non-physical abusive behaviors derived from the kinds of interpersonal relationships outside of the relationship between supervisors and subordinates. He also derived them from literature describing the actions suited to abusive supervision, and of physical behavior occurring in the relationship between pairs (male and female). In our study, we asked the participants to describe incidents of abusive supervision that they experienced or had known in their workplace. Procedures used in this study allow us to capture more detailed form which was considered as abusive behavior.

\section{Conclusions and Implications}

The development of the study and validation of the abusive supervision measure provided some important results. First, there were differences between abusive supervision indicators that were found in this study and the indicators in Tepper (2000). Although from the 25 indicators that were found in this study, only five indicators had similarities with the 15 abusive supervision indicators in Tepper (2000), some other items in this study have been proposed by other researchers in the U.S. as being supervisor's abusive behavior. Second, in contrast to Tepper (2000) which found the abusive supervision construct as a unidimensional one, and Mitchell and Ambrose (2007) who found a two-dimensional supervision abusive, the current study found a 3-dimensional abusive supervision. The dimensions were angry-active abuse, humiliation-active abuse, and passive abuse. This study found that in general there is a similarity in abusive supervision's items both in the U.S. and in Indonesia. Nevertheless, there are some items that have not been captured in the items of abusive supervision in the U.S. It is possible that those items appear because of the effects of cultural factors, industry characteristics, and the research method used in this study.

Referring to some of the differences found in this study compared with the scales of Tepper (2000) and other researchers in the U.S., further research should investigate more deeply the effects of the Indonesian culture on the items of the abusive supervision. The 
resulting scale of this study is at an early stage. To increase the generalizing of constructs of abusive supervision, future studies need to validate it again in a different cultural context.

\section{References}

Aquino, K., S. Douglas, and M. J. Martinko. 2004. Overt anger in repsonse to victimization: attributional style and organizational norms as moderators. Journal of Occupational Health Psychology 9 (2):152-164.

Aryee, S., X. C. Zhen, S. Li-Yun, and A. D. Yaw. 2007. Antecedents and outcomes of abusive supervision: Test of a trickle-down model. Journal of Applied Psychology 92 (1): 191-201.

Burris, E. R., J. R. Detert, and D. S. Chiaburu. 2008. Quitting before leaving: The mediating effects of psychological attachment and detachment on voice. Journal of Applied Psychology 93 (4): 912-922.

Detert, J. R., L. K. Trevino, E. R. Burris, and M. Andiappan. 2007. Managerial modes of influence and counterproductiveity in organizations: A longitudinal business-unit-level investigation. Journal of Applied Psychology 92 (4): 993-1105.

Duffy, M. K., and W. J. Ferrier. 2003. Birds of a feather...? How supervisor-subordinate dissimilarity moderates the influence of supervisor behaviors on workplace attitudes. Group and Organization Management 28 (2): 217-248.

Hancock, P. 2000. The lived experience of female factory in rural West Java. Labour and Management in Development Journal 1 (1): 1-18.

Harris, K. J., K. M. Kacmar, and S. Zivnuska. 2007. An investigation of abusive supervision as a predictor of performance and the meaning of work as a moderator of the relationship. The Leadership Quarterly 18: 252-263.

Hofstede, G. 1998.Think locally, act globally: Cultural constraints in personnel management. Management International Review 38: 7-26.

Hofstede, G. 2007. Asian management in the $21^{\text {st }}$ century. Asia pacific Journal of Management 24: 411-420

Irawanto, D. W., and P. H. Ramsey. 2011. Paternalistic leadership and employee responses in Javanese culture. Gadjah Mada International Journal of Business 13 (2): 185-203.

Khatri, N. 2009. Consequences of power distance orientation in organizations. The Journal of Business Perspective 13 (1) (January-March): 1-9.

Kirkman, B. L., G. Chen, J. L. Farh, X. C. Zhen, and K. B. Lowe. 2009. Individual power distance orientation and follower reactions to transformational leaders: a cross-level, cross-cultural examination. Academy of Management Journal 52 (4): 744-764.

Larson, H. H., and B. H. Kleiner. 1992. Understanding and effectively managing Asian employees. Equal Opportunities International 11 (2): 18-22.

Lawshe, C. H. 1975. A quantitative approach to content validity. Personnel Psychology 28: 563-575.

Lian, H., D. L. Ferris, and D. J. Brown. 2012b. Does power distance exacerbate or mitigate the effects of abusive supervision? It depends on the outcome. Journal of Applied Psychology 97 (1): 107-123.

Liew, S., Y. Ma, S. Han, and Aziz-Zadeh. 2011. Who's afraid of the boss: cultural differences in social hierarchies modulate self-face recognition in Chinese and Americans. Plos One 6 (2): 1-8. 
Mitchell, M. S., and M. L. Ambrose. 2007. Abusive supervision and workplace deviance and the moderating effects of negative reprocity beliefs. Journal of Applied Psychology 92 (4): 1159-1168.

Morison, E. W., Y-R.Chen, and S. R. Salgado. 2004. Cultural differences in newcomer feedback seeking: A aomparison of the United States and Hong Kong. Applied Psychology: An International Review 53 (1): $1-22$.

Nelson, R. J. 1998. Abusive supervision and subordinates' coping strategies. Dissertation. The graduate school University of Kentucky.

Ralston, D. A., P. Hallinger, C. P. Egri, and S. Naothinsuhk. 2005. The effects of culture and life stage on workplace strategies of upward influence: A comparison of Thailand and the United States. Journal of World Business 40: 321-337.

Samnani, A. 2013. The early stages of workplace bullying and how it becomes prolonged: The role of culture in predicting target responses. Journal of Business Ethics 113:119-132.

Scandura, T., and P. Dorfman. 2004. Leadership research in an international and cross-cultural context. The Leadership Quarterly 15: 277-307.

Shultz, K. S., and D. J. Whitney. 2005. Measurement Theory in Action: Case Studies and Exercise. New Delhi: Sage Publication, Inc.

Templeton, G. F., B. R. Lewis, and C. A. Snyder. 2002. Development of a measure for the organizational learning contruct. Journal of Management Information Systems 19 (2) (Fall): 175-218.

Tepper, J. P. 2000. Consequences of abusive supervision. Academy of Management Journal 43: 178-190.

Tepper, B. J. 2007. Abusive supervision in work organizations: review, synthesis, and research agenda. Journal of Management 33: 261-289.

Tepper, B. J., S. E. Moss, D. E. Lockhart, and J. C. Carr. 2007. Abusive supervision, upward maintenance communication, and subordinates' psychological distress. Academy of Management Journal 50 (5): $1169-1180$

Tepper, B. J., C. A. Henle, L. S. Lambert, and M. K. Duffy. 2008. Abusive supervision and subordinates' organization deviance. Journal of Applied Psychology 93 (4): 721-732.

Tepper, B. J., J. C. Carr, D. M. Breaux, S. Geider, C. Hu, and H. Wei. 2009. Abusive supervision, intention to quit, and employees' workplace deviance: A power/dependence analysis. Organizational Behavior and Human Decision Processes (article in press).

Thau, S., R. J. Bennet, M. S. Mitchell, and M. B. Marrs. 2009. How management style moderates the relationship between abusive supervision and workplace deviance: An uncertainty management theory. Organizational Behavior and Human Decision Process 108: 79-92.

Wright, L., and V. C. Tellei. 1993. Women in management in Indonesia. International Studies of Management and Organization 23 (4):19-45.

Zellars, K. L., B. J. Tepper, and M. K. Duffy. 2002. Abusive supervision and subordinates' organizational citizenship behavior. Journal of Applied Psychology 87 (6): 1068-1076. 
